\title{
Los hidrocarburos en el Gobierno de Evo Morales: extractivismo nacionalista con presencia extranjera $^{1}$
}

\author{
Hydrocarbons in the government of Evo Morales: nationalist \\ extractivism with foreign presence
}

Recibido: 14 de enero de 2015- Revisado: 06 de febrero de 2015 - Aceptado: 14 de julio de 2015

Natalia Ceppi ${ }^{2}$

\begin{abstract}
Resumen
El objetivo de este artículo es reflexionar sobre el accionar del Gobierno de Evo Morales en la industria hidrocarburífera nacional, considerando sus repercusiones en el vínculo del Estado con las empresas transnacionales y con Argentina y Brasil, en su condición de socios energéticos. Este estudio se propone, mediante un análisis bibliográfico, documental y de datos estadísticos, corroborar el supuesto que, pese a la reformulación de los contratos energéticos, el Movimiento al Socialismo ha fortalecido la reproducción del patrón extractivista donde conviven el Estado y la inversión extranjera y sin lograr avances significativos en la industrialización del sector.
\end{abstract}

\section{Palabras clave}

Bolivia, hidrocarburos, nacionalización, extractivismo, empresas transnacionales.

\begin{abstract}
The aim of this article is to reflect on the actions of the government of Evo Morales in the national oil industry, considering its impact on the state link with transnational corporations and with Argentina and Brazil, in their capacity as energy partners. This study aims, through a bibliographical, documentary and statistical data analysis, to corroborate the assumption that despite the reformulation of energy contracts, the Movimiento al Socialismo has strengthened the reproduction of the extractive pattern where the state and foreign investment coexist and without achieving a significant progress in the industrialization of the sector.
\end{abstract}

\section{Keywords}

Bolivia, hidrocarbons, nationalization, extractivism, ttransnational companies.
${ }^{1}$ Este artículo forma parte del proyecto de investigación "La cuestión energética y su reposicionamiento como tema prioritario en las políticas exteriores de Argentina, Bolivia y Brasil (2003-2011): estudio en perspectiva comparada vinculando factores domésticos y sistémicos" financiado por el Consejo Nacional de Investigaciones Científicas y Técnicas (Conicet).

${ }^{2}$ Doctora en Relaciones Internacionales de la Universidad Nacional de Rosario (UNR) (Rosario, Argentina). Profesora titular de Derecho Consular y Diplomático de la Licenciatura en Relaciones Internacionales, Facultad de Ciencia Política y Relaciones Internacionales (UNR). Investigadora asistente del Conicet.

Correo electrónico:

nataliaceppi@yahoo.com.ar

Para citar este artículo use: Ceppi, N. (2016). Los hidrocarburos en el Gobierno de Evo Morales: extractivismo nacionalista con presencia extranjera. Revista Civilizar Ciencias Sociales y Humanas, 16(30), 175-190. 


\section{Introducción}

Los recursos naturales en general, pero particularmente los energéticos, pueden caracterizarse como bienes estratégicos. Son indispensables para el sostenimiento de la economía de cualquier país y contribuyen a la satisfacción de las necesidades poblacionales y el desenvolvimiento de un sinnúmero de actividades productivas. Dicha situación cobra una connotación especial en aquellos Estados que, como Bolivia, al poseer una matriz comercial poco diversificada, han hecho de la explotación del sector hidrocarburífero el "sostén" de la economía nacional.

El presente siglo trajo aparejado un conjunto de cambios para la industria energética del país andino, producto de la incidencia de acontecimientos del orden doméstico e internacional. Los enfrentamientos violentos que transcurrieron entre septiembre y octubre de 2003 que derivaron en la denominada "Guerra del Gas" y en la dimisión de Gonzalo Sánchez de Lozada en su segundo mandato -iniciado en 2002-, dieron mayor visibilidad a los reclamos sociales que cuestionaban los resultados de la capitalización de Yacimientos Petrolíferos Fiscales Bolivianos (YPFB) ${ }^{1}$.Paralelamente, los análisis de la Comisión Económica para América Latina y el Caribe (Cepal) dan cuenta de que en la primera década del siglo XXI, el valor de las exportaciones de los productos primarios de la región -entre ellos, los hidrocarburos- experimentaron un "auge inédito", convirtiéndose en un factor clave para mejorar el desempeño macroeconómico y el posicionamiento fiscal de los países exportadores (Acquatella, Altomonte, Arroyo, \& Lardé, 2013, p. 9).

En este contexto se inserta la llegada de Evo Morales a la presidencia de la nación en enero de 2006 a través del Movimiento al Socialismo (MAS). Desde los inicios de su gestión -y aún en plena campaña electoral- la nacionalización de los hidrocarburos ocupó un lugar prioritario en su programa de Gobierno, presentándola como un paso imprescindible para avanzar en la reformulación del vínculo Estado-inversión extranjera y en la puesta en marcha de un nuevo modelo económico.

El artículo propone reflexionar sobre el accionar del MAS en el sector energético nacional y sus implicancias en la relación del Estado con las empresas transnacionales y los países importadores regionales. Ambos actores son clave en la dimensión económico-comercial de una política exterior cuya base es primario-exportadora. El supuesto disparador es que, teniendo en cuenta las limitaciones de la economía boliviana, el ciclo de los hidrocarburos se constituye -desde la segunda mitad de los ochenta- en el soporte sobre el cual los policy makers diagramaron sus respectivos programas de Gobierno. La administración Morales no es una excepción a la regla y ha emprendido un proceso caracterizado por la convivencia entre el nacionalismo extractivista y la inversión extranjera.

El enfoque de este estudio es cualitativo y como tal procura realizarun abordaje exhaustivo, holístico de las cualidades del objeto a analizar. En este sentido, se retoman las afirmaciones de Hernández Sampieri, Fernández Collado y Baptista Lucio (2010), quienes sostienen que los enfoques cualitativos buscan "la expansión de los datos e información"; son abiertos, flexibles y no pretenden generalizar los resultados obtenidos sino comprender al fenómeno y su contexto (pp. 10-13). La referencia empírica proviene de las principales leyes y decretos que regulan el sector energético boliviano; los contratos gasíferos de Bolivia con Argentina y Brasil; los artículos especializados en la materia y los datos estadísticos elaborados por la Organización Latinoamericana de Energía (Olade), la Cepal, el Instituto Nacional de Estadísticas (INE) de Bolivia, la Unidad de Análisis de Políticas Sociales y Económicas (Udape) de Bolivia, YPFB, el Instituto Argentino del Petróleo y del Gas (IAPG) y la Agência Nacional do Petróleo, Gás Natural e Biocombustíveis (ANP) de Brasil. 
El abordaje teórico se inscribe en los lineamientos de la economía política de Monaldi (2010) -quien centra sus estudios en las industrias energéticas- $\mathrm{y}$ en los aportes de Gray Molina (2006) y Wanderley (2009) sobre las nociones de "economía de base estrecha" y el binomio patrón de desarrollo/ modelo económico. El trabajo se organiza en cuatro secciones, siguiendo los ejes que atraviesan el análisis de Monaldi (2010). La primera -los rasgos propios de la industria energética- identifica desde una óptica general los elementos más sobresalientes que hacen a su constitución como tal. Esto permite contar con un cuadro de situación para ahondar en las particularidades del caso boliviano en los apartados siguientes. La segunda sección -la dotación de recursos y sus característicastiene en cuenta indicadores como la relación producción/consumo y petróleo/gas y si es un país que se autoabastece o es deficitario en términos de energía. La tercera -el marco institucional y contractual- se focaliza en el marco jurídico existente y en la vinculación del Estado con las empresas transnacionales y los socios energéticos. La cuarta -los factores económicos- comprende indicadores tales como los ciclos de inversiones, la dependencia fiscal de la renta petrolera, el desempeño del sector y su conexión con la política ${ }^{2}$. Por último, en las conclusiones se realiza un balance de lo expuesto a lo largo del trabajo con miras a exponer los resultados más relevantes.

\section{El rubro energético: un rubro económico singular}

Es innegable que cada industria energética nacional reúne características que la convierten en única. No obstante, en el rubro hidrocarburífero se observan algunos indicadores que marcan una tendencia hacia la generalidad. Los trabajos de Acquatella et al. (2013), Mokrani (2008), Monaldi (2010), Nore (1981), Ruiz-Caro (2003), entre otros, distinguen la presencia de elementos como: la concentración geográfica de las reservas -en aquellos Estados o regiones que son intensivos en la actividad-; las oscilaciones en la recaudación fiscal que deriva de la explotación hidrocarburífera producto de la volatilidad de los precios internacionales; los diferentes grados de riesgo involucrados, según sus fases - de exploración o desarrollo- y los retos que enfrentan los gobiernos estatales para integrar el sector al resto de la economía y no quedar anclados en un esquema monoexportador.

Dentro del mix de los hidrocarburos, las proyecciones indican que el gas natural se perfila en el presente siglo como la principal fuente de energía alternativa al petróleo "por sus ventajas de tipo ambiental, eficiencia térmica y competitividad de los precios respecto a sus sustitutos" (Mokrani, 2008, p. 142). Según los datos de la Olade, en América Latina y el Caribe el gas natural es la energía que más se produce después del petróleo. En el periodo 1990-2011, el crecimiento promedio anual de la oferta ha sido de 4.69 \%, superando a Europa, Eurasia, Estados Unidos y Canadá gracias a la intensidad que adquirieron los intercambios regionales por las exportaciones de gas natural licuado (GNL) de Perú y Trinidad y Tobago y las ventas de gas de Bolivia hacia Argentina y Brasil y de Colombia a Venezuela (Ríos-Roca, 2012, p. 24).

Una característica del mercado gasífero es la formación de precios. A diferencia del petróleo que cotiza en el mercado mundial, el gas natural no cuenta con un mercado internacional consolidado, sino que el proceso de formación de precios depende de las modalidades de comercialización que se adopten o los rasgos del mercado de destino, aunque las tasas de ajuste se asocian con la cotización del petróleo (Mokrani, 2008, pp. 145-146).

En términos generales, Mokrani (2008) categoriza los criterios para la formación de precios de acuerdo con: la competencia gassustitutos; la competencia gas-gas; los precios de mercado y el costo de oportunidad. El 
primero simula las condiciones de competencia del gas respecto de sus sustitutos en el mercado de destino. En el segundo la valoración se establece cuando la nación exportadora toma el precio del mercado de destino. El tercer criterio suele utilizarse en los grandes mercados de consumo. Los exportadores son tomadores de precios, que pese a regirse por el juego de las fuerzas de mercado del país receptor, no se deja de lado la relación con la cotización del petróleo "que se constituye en marcador de los combustibles alternativos". El último criterio se conoce como "coste de la mejor alternativa perdida" (pp. 146-147) y puede presentarse en casos de economías cuya oferta de exportación excedentaria favorece políticas de captura de mercado o cuando desde la demanda no hay mejores alternativas de suministro.

\section{La dotación de recursos en Bolivia}

Al hacer un breve recorrido por la vida económica del país andino, se aprecia que históricamente ha dependido de los recursos naturales y las fases de su desarrollo se han identificado en ciclos, tales como el ciclo de la plata, el del estaño, la goma y el de los hidrocarburos, que desde mediados de los ochenta se convirtió en la principal fuente de ingresos fiscales (Gordon \& Luoma, 2008, p. 95; Morales, 2008, p. 2). En el escenario latinoamericano, Bolivia es uno de los principales productores de gas natural con el 10,8 \% del total (Molina-Ortiz, 2013).

Si bien en una primera lectura este porcentaje podría considerarse "poco significativo" ya que es superado ampliamente por Trinidad y Tobago (24,3\%), Argentina (21,7\%) y Venezuela $(18,9 \%)$, en realidad, para hacer un análisis más acabado deben tenerse en cuenta otros indicadores tales como su nivel de consumo -sobre todo la relación producción/consumo- y las particularidades "geológicas" del recurso. El nexo producción/consumo indica la posición de un Estado o región como importa- dor o exportador. Un índice mayor a 1 indica que el país es exportador, un índice igual a 1 muestra que la producción logra satisfacer la demanda doméstica y un índice menor a 1 revela que el país necesita recurrir a la importación de energía (Altomonte, Acquatella, Arroyo, Canales \& Jouravlev, 2013, p. 46).

En América Latina, la ratio promedio de este vínculo ha oscilado entre 1,1 y 1,4 pero en el caso de Bolivia su ratio de producción con respecto al consumo llega a 6 , superando "con creces" la media de la región (Altomonte et al., 2013, p. 50). La tabla 1 ilustra la posición de Bolivia con relación a los principales productores gasíferos latinoamericanos. Como puede observarse, su bajo nivel de consumo doméstico le permite concentrar sus esfuerzos en la exportación del producto sin poner en peligro el autoabastecimiento.

Tabla 1

Relación producción/consumo

\begin{tabular}{|lcc|}
\hline \multicolumn{1}{|c|}{ País } & $\begin{array}{c}\text { Producción gas } \\
\text { natural } \\
(\%)\end{array}$ & $\begin{array}{c}\text { Consumo gas } \\
\text { natural } \\
(\%)\end{array}$ \\
\hline Trinidad y Tobago & 24,3 & 14,1 \\
\hline Argentina & 21,7 & 30,8 \\
\hline Venezuela & 18,9 & 22,7 \\
\hline Bolivia & 10,8 & 2,2 \\
\hline
\end{tabular}

Fuente: elaboración propia con base en Molina-Ortiz, 2013.

Otro dato distintivo del caso boliviano es que las reservas gasíferas son básicamente "secanas", es decir, que su explotación no se asocia a la explotación del petróleo como ocurre, por ejemplo, con Venezuela (MirandaPacheco, 2009, p. 197; Villegas-Quiroga, 2004, p. 84). Esto implica que para producir gas, las empresas no requieren destinar recursos a la producción de petróleo; situación que revaloriza su posición como proveedor gasífero en un contexto vecinal de demanda en ascenso. 


\section{El marco jurídico y las empresas transnacionales}

Evo Morales obtuvo su primera victoria presidencial el 18 de diciembre de 2005 con el $53,74 \%$ de los votos. Crítico del neoliberalismo pero especialmente del proceso de capitalización de YPFB en los años noventa ${ }^{3}$, Morales propugnó la necesidad de poner en marcha una reestructuración del vínculo del Estado con la economía y la sociedad con miras a instalar-de manera paulatina- un modelo sociopolítico de características más inclusivas. Para avanzar en este cometido, como primera medida, el oficialismo concentró sus esfuerzos en reposicionar la figura del Estado como promotor del desarrollo nacional (Estado Plurinacional de Bolivia, Ministerio de Planificación del Desarrollo, 2006). Teniendo en cuenta el peso del rubro hidrocarburífero en la economía boliviana, este se convirtió en un destino prioritario de su programa de nacionalización, que en la práctica, implicaría un desafío complejo y en ocasiones conflictivo.
La Ley de Capitalización (1544 de 1994), la Ley de Hidrocarburos (1689 de 1996) y el Decreto Supremo 24806 de 1997 fueron los instrumentos jurídicos que generaron un sector transnacionalizado en su totalidad y el relegamiento del Estado al cobro de regalías sin capacidad alguna de incidir en su gestión. A esto debe agregarse que, entre fines de la década del noventa y los primeros años del siglo XXI, comenzó a cobrar notoriedad la "brecha" entre las "promesas" de la liberalización y sus resultados más sobresalientes. Según Sánchez de Lozada (19931997) la capitalización de YPFB devendría en el fortalecimiento del potencial económico de la industria; la atracción de tecnología a través de la Inversión Extranjera Directa; el incremento de puestos de trabajo y el mejoramiento de la economía y las condiciones de vida (Gordon \& Luoma, 2008, p. 97). Sin embargo, la industria no fue modernizada; no se crearon nuevos puestos de trabajo - unos dos mil trabajadores de YPFB fueron despedidos (Fernández-Terán, 2009, p. 49)y los indicadores sociales evidenciaron que los ingresos de la renta petrolera no se canalizaron para combatir la pobreza y la desigualdad.

Tabla 2

Transnacionalización del sector energético boliviano

\begin{tabular}{|c|c|c|}
\hline Normativa & Resultados del marco jurídico & Otros resultados \\
\hline Ley 1544 de 1994 & $\begin{array}{l}\text { Fraccionamiento de YPFB en dos unidades de exploración y producción } \\
\text {-Chaco y Andina- y una de transporte - Transredes- }\end{array}$ & $\begin{array}{l}\text { No hubo inversiones en la } \\
\text { expansión de la infraestructura } \\
\text { doméstica }\end{array}$ \\
\hline $\begin{array}{l}\text { Ley } 1689 \text { de } 1996, \\
\text { decreto supremo } \\
24419 \text { de } 1996\end{array}$ & $\begin{array}{l}\text { - Suscripción de contratos de riesgo compartido } \\
\text { - Reclasificación de la mayoría de los campos de "existentes a nuevos"* } \\
\text { - Disminución del pago de regalías e impuestos a los operadores ener- } \\
\text { géticos del } 18 \% \text { al } 50 \% \text { sobre el total del valor de la producción por } \\
\text { política de reclasificación de campos }\end{array}$ & $\begin{array}{l}\text { Al } 2005 \text {, la pobreza moderada al- } \\
\text { canzaba al } 60,6 \% \text { de la población; } \\
\text { la pobreza extrema al } 38,2 \% \text { y el } \\
\text { coeficiente de Gini era de } 0,60\end{array}$ \\
\hline $\begin{array}{l}\text { Decreto supremo } \\
24806 \text { de } 1997\end{array}$ & $\begin{array}{l}\text { Otorgamiento de la propiedad de los hidrocarburos a los operadores } \\
\text { energéticos en Boca de Pozo }\end{array}$ & $\begin{array}{l}\text { La tasa de desempleo abierto al } \\
2005 \text { era del } 5,45 \% \text { frente al } 4,79 \\
\% \text { correspondiente al año } 2000\end{array}$ \\
\hline $\begin{array}{l}\text { Decreto supremo } \\
25588 \text { de } 1999\end{array}$ & $\begin{array}{l}\text { Adjudicación de las refinerías de YPFB -Gualberto Villarroel y Guiller- } \\
\text { mo Elder Bell- al consorcio formado por Petrobras y Pérez Companc** }\end{array}$ & \\
\hline
\end{tabular}

Nota: * Los campos "nuevos" eran los campos descubiertos con posterioridad a la promulgación de la ley 1689 de 1996 . Fue una "política de incentivo a la IED" porque gran parte de los campos que fueron definidos como "nuevos"-para que las empresas tributaran el $18 \%$ y no el $50 \%$ - ya estaban en producción antes de la ley en mención. ** En 2003 Petrobras adquirió la totalidad de las acciones de las refinerías al comprar el paquete accionario de Pérez Companc.

Fuente: elaboración propia con base en la normativa señalada, Arze-Vargas, 2009; Gandarillas-González, 2008; INE, s.f.; Soliz-Rada, 2003; Udape, s.f.; Villegas-Quiroga, 2004. 
Frente a este panorama, en su discurso de asunción presidencial, el 22 de enero de 2006, el primer mandatario afirmó:

No quisiéramos un Estado mendigo -lamentablemente nos han convertido en mendigos-, no quisiéramos que Bolivia, su Gobierno, sus equipos económicos vayan a pedir limosna de Estados Unidos, de Europa o de Asia. Quisiera que esto se termine, y para que termine eso estamos en la obligación de nacionalizar nuestros recursos naturales. El nuevo régimen económico de nuestra Bolivia deben ser fundamentalmente los recursos naturales (Morales, 22 de enero de 2006).

A escasos meses de estadía en el poder y aprovechando un periodo de precios internacionales altos en materia energética, Evo Morales anunció la nacionalización de los hidrocarburos bolivianos a través del decreto 28701 "Héroes del Chaco". Esta normativa se enmarca en la Ley de Hidrocarburos (3058 de 2005), sancionada durante el breve mandato de Carlos Mesa-Gisbert (2003-2005), quien ocupó el ejecutivo tras la dimisión de Sánchez de Lozada por los episodios de la "Guerra del Gas". Uno de sus aspectos más novedosos se presentó en el área impositiva porque creó el impuesto directo a los hidrocarburos (IDH), cuya alícuota es del $32 \%$ del total de la producción medida en el punto de fiscalización (art. 55, Ley 3058 de 2005). De este modo, los operadores que se encuentran en la cadena hidrocarburífera boliviana deben pagar al Estado el $50 \%$ del valor de la producción, que resulta de la suma entre el $18 \%$ de regalías y participaciones y el $32 \%$ del IDH (art. 55, Ley 3058 de 2005).

¿Qué dispuso el decreto 28701 de 2006 ? Entre los puntos más sobresalientes, se encuentran: a) "la propiedad, la posesión y el control" de los recursos naturales hidrocarburíferos del país recaen en el Estado que a través de YPFB asume la comercialización para el mercado doméstico y los destinos de exportación (arts. 1 y 2)-; b) el Estado procura la nacionalización de al menos el $51 \%$ de las acciones de las empresas Chaco, Andina, Transredes, Petrobras Bolivia Refinación y la Compañía Logística de Hidrocarburos de Bolivia (CLHB) (art. 7); c) empresas transnacionales -aquellas que deseen continuar operando en el país- deben firmar nuevos contratos con YPFB en el marco de la normativa hidrocarburífera ${ }^{4}$ o retirarse del sector (art. 3)-; y d) impuestos y regalías -equivalen al $50 \%$ sobre el valor de la producción de acuerdo con la ley 3058 de 2005 y un $32 \%$ adicional a favor de YPFB durante el periodo de transición 20062007, para los campos con una producción certificada de gas natural superior a los cien millones de pies cúbicos diarios al 2005 (art. 4)-.

Rodríguez Cáceres (2008), especialista en la temática hidrocarburífera, deja entrever en su análisis del decreto 28701 de 2006, que en la nacionalización promulgada por el MAS confluyen algunos aspectos que se anclan básicamente en lo "declarativo" y otros que intentan avanzar más allá de la ley 3058 de 2005 (p. 127). En otras palabras, por un lado, el mencionado decreto no aclara cuáles serán los pasos a seguir para garantizar el cumplimiento de la normativa, sobre todo en lo que respecta al deber de las empresas contratistas de entregar la producción a YPFB y al ejercicio propietario del Estado. Por otro, la nacionalización del $51 \%$ de las acciones de las compañías capitalizadas $\mathrm{y}$ de las que fueron privatizadas fuera de la capitalización, tales como Petrobras Bolivia Refinación y CLHB, da cuenta de los intentos del Estado por tener una presencia mayor en el upstream y downstream de la industria. Así mismo, la obligación de las transnacionales de adecuarse a las modalidades de contrato establecidas por la ley 3058 de 2005 permitió incrementar la participación estatal en la renta petrolera porque deben cancelar el $50 \%$ del valor de la producción (Rodríguez-Cáceres, 2008, pp. 127-135).

Para Mayorga (2008) la nacionalización de 2006 refleja un rasgo típico de la gestión 
gubernamental del MAS: la combinación de una retórica radical con decisiones moderadas, puesto que no hubo confiscación de las inversiones extranjeras sino una reformulación de los contratos firmados entre el Estado y los operadores energéticos para mejorar las condiciones tributarias del primero (p. 136).

En el plazo que fijó el decreto 28701 de 2006 (seis meses), YPFB y las transnacionales suscribieron 44 -quedaron finalmente 43 tras la cancelación del contrato con Canadian Energy y Monelco SRL en 2009-, los cuales entraron en vigencia el 2 de mayo de 2007. Sin desconocer la existencia de particularidades, todos ellos poseen como características más destacadas que al titular no se le confiere la propiedad de los yacimientos ni de los hidrocarburos producidos y que las operaciones realizadas por las petroleras son a cuenta exclusiva, al igual que los riesgos, percibiendo a cambio una retribución o pago por sus servicios (Carvajal, 21 de agosto de 2012).

A lo anterior debe sumarse que tras el pago de las regalías y el IDH, YPFB le reconoce a las transnacionales un monto por concepto de "costos recuperables" -en materia de contratación de personal, transporte, seguros de trabajo, administración, etc.- que se establecen en los anexos de los contratos firmados ${ }^{5}$. Una vez descontados estos montos, la ganancia resultante se distribuye entre YPFB y el titular del contrato en cuestión, según los porcentajes de participación acordados en cada caso (Carvajal, 21 de agosto de 2012).

Como parte de su "retórica radical" el Gobierno boliviano ha promocionado estos acuerdos como "contratos de servicios"; situación que convertiría a las transnacionales en meras proveedoras de servicios sin intervenir ni en la exploración ni en la explotación del sector ${ }^{6}$. No obstante, el Observatorio Boliviano de Industrias Extractivas (OBIE) sostiene que los contratos firmados en 2006 reúnen la califica- ción de "híbridos" -también lo hace el análisis de Zaratti (2 octubre de 2013) - porque poseen elementos de las tres modalidades de contrato que fija la ley 3058 del 2005 (OBIE-CEDLA, 2006, pp. 4-5).

Frente a la falta de capacidad de YPFB -y por ende del Estado boliviano- para asumir la operación de los pozos hidrocarburíferos, tras la renegociación contractual, las empresas permanecieron a cargo en calidad de contratistas "remuneradas", "con un porcentaje que se acerca a $1 / 3$ del valor de las ventas" (Zaratti, 2 de octubre de 2013). El anuncio de nacionalización dio comienzo a un periodo de redefinición del vínculo Estado/transnacionales pero también repercutió en la relación con sus principales socios comerciales: Argentina y Brasil. Retomando la investigación de Altomonte et al. (2013), tanto Argentina como Brasil poseen un nexo producción/consumo negativo, puesto que en el primer caso la ratio es de 0,9 y en el segundo de 0,7 (pp. 47-49). Esta situación se tradujo en dificultades -aunque en diferentes grados- para cubrir las necesidades de consumo gasíferas por cuenta propia y frente a ello, sus respectivos Gobiernos solicitaron la provisión desde Bolivia.

La decisión argentina de iniciar la compra de gas natural boliviano se plasmó en la firma de un convenio temporal el 21 de abril de 2004 y fue motivada por la crisis energética ${ }^{7}$ que eclosionó en el mes de marzo, cuando la administración de Néstor Kirchner (2003-2007) tuvo que reducir e incluso suspender los envíos de gas a Chile para sustentar el consumo doméstico ${ }^{8}$. En cambio, en el caso brasilero, las importaciones gasíferas se inscriben como parte de una estrategia política de expandir el uso del hidrocarburo en la matriz energética nacional, a fin de reducir el uso del fuel oil y otras energías de menor calidad en las actividades industriales del sudeste del país (Fernández-Saavedra, 2014, p. 48). Así, en 1996 YPFB y Petrobras suscribieron dos contratos: uno de compraventa por un periodo de veinte años 
con un volumen final de treinta $\mathrm{MMm}^{3}$ diarios y el otro para la construcción de un gasoducto que atraviesa los Estados de Mato Grosso del Sur, São Paulo, Santa Catarina, Paraná y Río Grande del Sur, el cual fue inaugurado en 1999. De este deriva otra conexión, el gasoducto de Cuiabá, que abastece de gas natural a una termoeléctrica ubicada en Mato Grosso (Villegas-Quiroga, 2004, pp. 117-119).

Unidos por la sorpresa, Néstor Kirchner y Lula da Silva (2003-2010) respaldaron la medida de nacionalización por considerarla una decisión soberana de un Estado y acordaron en la Cumbre de Presidentes de Puerto Iguazú -mayo de 2006-, renegociar los contratos de compraventa de gas natural (República Argentina, 4 de mayo de 2006).

Los resultados de los procesos de negociación emprendidos por los Gobiernos de Argentina y Brasil tuvieron más diferencias que similitudes, precisamente porque sus capacidades de negociación no eran las mismas como tampoco lo eran las condiciones en las cuales se encontraban al conocerse el decreto 28701 de 2006. En el caso argentino, los funcionarios ministeriales se sentaron en la mesa de negociación con pocos elementos a su favor: reservas probadas de gas natural en descenso -de $612.291 \mathrm{MMm}^{3}$ a $438.921 \mathrm{MMm}^{3}$ en el periodo 2003-2005- (IAPG, s.f.); un consumo en aumento -alrededor del $12 \%-$ y la falta de una empresa que fuera representativa del Estado nacional operando en Bolivia. Por el contrario, Brasil en los primeros años del siglo XXI tenía un contexto de consumo reducido -el gas natural representaba entre el $3 \%$ y el $5 \%$ de la matriz energética nacional-; reservas con un comportamiento positivo "leve" -de 245.340 $\mathrm{MMm}^{3}$ a $306.395 \mathrm{MMm}^{3}$ en los años 2003 y 2005 (ANP, 2013) - y la presencia de Petrobras en los campos gasíferos bolivianos que operaba el 45,9\% de las reservas probadas y probables y monopolizaba las actividades de refinación (YPFB, 2009).
El 19 de octubre de 2006, YPFB y Energía Argentina Sociedad Anónima (Enarsa) suscribieron un contrato de compraventa de gas natural por un lapso de veinte años y con un compromiso de envío que irá in crescendo hasta alcanzar un volumen final de $27,7 \mathrm{MMm}^{3}$ por día (Energía Argentina S.A. -Enarsa, 19 de octubre de 2006). Recorriendo su articulado, puede afirmarse que el contrato Enarsa-YPFB deja bien en claro los roles de ambas empresas, es decir, como importador y exportador, sin mencionar la posibilidad de participación por parte de Argentina en las actividades de exploración, explotación o producción en la industria energética boliviana. Esta relación centrada solo en un compromiso de compraventa indica cierta vulnerabilidad por parte de Argentina frente a posibles cambios de las reglas de juego, porque al carecer de incidencia en el upstream o downstream de la nación vecina no dispone de elementos que le permitan ampliar sus márgenes de maniobra ante situaciones de dificultad.

Tras arduas negociaciones, Petrobras y YPFB firmaron un nuevo contrato el 28 de octubre de 2006. Desde la empresa brasilera se informó que este acuerdo regula las actividades de explotación y producción en Bolivia sin atender las modificaciones en materia de precios o el tratamiento de las refinerías propiedad de Petrobras ${ }^{9}$. Con respecto a sus ítems más sobresalientes, se subraya que Petrobras conserva el desarrollo de los campos que alimentan las necesidades gasíferas de Brasil; los activos de la compañía son propiedad de Petrobras hasta la finalización del acuerdo y se incorporó la cláusula de costos recuperables ${ }^{10}$ (Petrobras, 31 de octubre de 2006). Teniendo en cuenta estas condiciones y retomando la definición de contrato de producción compartida de la ley 3058 de 2005 (nota al pie 4), este acuerdo se asemeja más a esta modalidad que a un contrato de servicios, porque Petrobras en calidad de titular participa en la 
producción luego del pago de los impuestos correspondientes.

\section{Los factores económicos (y otros)}

El proceso de nacionalización ha sido muy criticado por los sectores que demandaban un accionar con políticas confiscatorias o de expropiación, pero el Gobierno no estaba en condiciones de prescindir de la inversión extranjera. Esta última era necesaria para reactivar tanto el sector como la economía y a partir de allí establecer políticas de distribución. Si bien, al momento de hacer referencia a la nacionalización, Morales apela a su retórica radical -en palabras de Mayorga (2008)-, en su primera presentación ante la Asamblea General de las Naciones Unidas en 2006, dejó en claro su postura:

Cuando hablamos de recuperar nuestros recursos naturales, bajo esa campaña sucia de acusaciones nos dicen que el Gobierno de Evo Morales no va a respetar la propiedad privada. Quiero decirles que en mi Gobierno se respetará la propiedad privada. Es verdad que necesitamos inversión; necesitamos socios, no patrones, no dueños de nuestros recursos naturales. Entendemos perfectamente que un país subdesarrollado necesita inversión (Morales, 19 de septiembre de 2006, p. 36).

Al momento de emprender la nacionalización, el MAS supo reconocer las limitaciones del entorno, de modo que, procuró reducir, en la medida de lo posible, la brecha entre los beneficios que percibían los operadores energéticos y aquellos que recibía el Estado para ampliar el margen de participación de YPFB en la recaudación fiscal. De esta manera, factores como los precios internacionales altos en el rubro energético; la incorporación de la cláusula "costos recuperables" y la existencia de mercados cautivos como Argentina y Brasil, dinamizaron los flujos de inversión y, en consecuencia, la renta petrolera.
Tabla 3

Evolución de la inversión en el sector hidrocarburífero (en millones de dólares)

$\begin{array}{ccccccccc}\text { Año } & 2005 & \mathbf{2 0 0 6} & \mathbf{2 0 0 7} & \mathbf{2 0 0 8} & \mathbf{2 0 0 9} & \mathbf{2 0 1 0} & \mathbf{2 0 1 1} & \mathbf{2 0 1 2} \\ \text { Montos } & 246 & 273 & 299 & 384 & 612 & 782 & 1293 & 1593\end{array}$

Fuente: YPFB, 2013a.

Tabla 4

Evolución renta petrolera del Estado boliviano (en millones de dólares)

\begin{tabular}{|ccccccccc|}
\hline Año & 2005 & 2006 & 2007 & 2008 & 2009 & 2010 & 2011 & 2012 \\
\hline Montos & 673 & 1474 & 1533 & 2099 & 2138 & 2235 & 2989 & 4292 \\
\hline
\end{tabular}

Fuente: YPFB, 2013b.

Como se observa en la tabla 3 , los volúmenes de inversión ascendieron notablemente a partir de 2010. Desde YPFB se sostiene que en esta subida tuvo una incidencia significativa la firma de la adenda al contrato Enarsa-YPFB en marzo de 2010, que entre otras cuestiones, incorporó una garantía de pago a favor de YPFB. Con este instrumento, las transnacionales que entregan el gas a YPFB para su posterior venta a Enarsa, obtuvieron un mayor nivel de certidumbre y en palabras del expresidente de YPFB "es un hito [que] destrabó las inversiones de las empresas petroleras que operan en Bolivia" (Villegas-Quiroga, 2004; YPFB, 2013a).

La evolución positiva de la renta energética (véase tabla 4) le ha permitido a la administración Morales destinar gran parte de los recursos del Estado al establecimiento de políticas sociales, para atender deficiencias específicas en materia de salud y educación y mediante un "efecto derrame" abordar la pobreza y la falta de inclusión. Entre las políticas sociales con mayor repercusión se encuentran los programas de transferencias monetarias -que pueden ser condicionadas o no-, bono Juancito Pinto (BJP), bono Juana Azurduy (BJA), renta dignidad $(\mathrm{RD})$, entre otras, mediante las cuales se procura romper con la transmisión intergeneracional de las condiciones de vulnerabilidad y extender el campo de la protección social del Estado. 
Tabla 5

Políticas sociales/erogación del Estado en millones de bolivianos (BOB)

\begin{tabular}{|c|c|c|}
\hline Política & Objetivo & Erogación del Estado \\
\hline BJP & Incentivar la matriculación y la escolaridad & $\begin{array}{l}\text { Año de inicio 2006: } 227,3 \text { millons de BOB } \\
\text { Año } 2012^{*}: 381,9 \text { millones de BOB }\end{array}$ \\
\hline BJA & Reducir la mortalidad materno-infantil & $\begin{array}{l}\text { Año de inicio 2009: } 55 \text { millones de BOB } \\
\text { Año 2012: 177,1 millones de BOB }\end{array}$ \\
\hline RD & Mejorar las condiciones de la seguridad social & $\begin{array}{l}\text { Año de inicio 2008: } 1407,6 \text { millones de BOB } \\
\text { Año 2012: } 1979,6 \text { millones de BOB }\end{array}$ \\
\hline
\end{tabular}

De acuerdo con los datos oficiales estos programas de transferencias monetarias han "ayudado" a mejorar algunos indicadores sociales, en particular, la RD. Entre 2005 y 2011, los niveles de pobreza pasaron del 60,6 $\%$ al $45 \%$ y la desigualdad de 0,60 al 0,46 , según el coeficiente de Gini (Udape, s.f.) ${ }^{11}$. En específico, el otorgamiento de los bonos Juancito Pinto y Juana Azurduy ha posibilitado aumentar la tasa de asistencia escolar del 79,71 $\%$ en 2001 al 83,54 \% en 2012 y la presencia de partos institucionalizados declarados - del 53,04 $\%$ al 67,30\%-a lo largo de la década, según los resultados del Censo Nacional de Población y Vivienda de Bolivia de $2012^{12}$.

Por otro lado, este periodo de bonanza económica puso nuevamente de manifiesto cuán dependiente es la economía de la renta energética. Al analizar la estructura del comercio externo, puede observarse que las ventas de los productos tradicionales (hidrocarburos y minerales) suelen cuadriplicar o aún más los ingresos provenientes de los no tradicionales, tales como los textiles, la joyería, la quinua o la soya, entre otros. También se desprende que Brasil y Argentina ocupan el primer y el segundo puesto, respectivamente, dentro del esquema de países con los cuales Bolivia posee intercambios comerciales. No es para nada menor que en sendas vinculaciones, las exportaciones del hidrocarburo boliviano representan alrededor del $90 \%$ de las ventas totales que el Estado andino realiza a sus vecinos (IBCE, 2013; 2014).

Los datos expuestos permiten aplicar las nociones de Gray-Molina (2006) y Wanderley (2009) sobre una constante en la historia de Bolivia: a lo largo de la historia el patrón de desarrollo ha permanecido sin alteraciones, mientras que el modelo económico sí ha atravesado por diferentes etapas. Para estos autores, el patrón de desarrollo refiere a la dotación de factores productivos de una economía determinada -en el caso de Bolivia, dicho patrón implica que es un Estado primarioexportador- y el modelo económico representa cómo se administra el patrón de desarrollo, pudiendo ser con un Estado intervencionista o con un esquema de índole liberal. Gray-Molina (2006) lo sintetiza afirmando que "el modelo es la forma, [...] el patrón es el contenido, la sustancia" (p. 65).

La gestión que el Gobierno de Morales hace de la economía nacional, se inscribe en esta lógica. En gran medida, el MAS reproduce la idea de "ciclos" económicos a través de la explotación gasífera, donde el dinamismo económico depende de la exportación de un producto con escaso valor agregado, forjando así una economía de "base estrecha" y con una fuerte impronta extractivista (Gray-Molina, 2006, p. 66; Wanderley, 2009. 
p. 215). Para impulsar la industrialización del sector, el ejecutivo dispuso la puesta en marcha de algunos proyectos, entre los cuales están las plantas de separación de licuables de Río Grande y Gran Chaco. Otros, en cambio, aún están en una etapa de planificación. En definitiva, falta mucho camino por recorrer para la concreción de emprendimientos orientados a obtener productos con valor agregado basados en el gas natural ${ }^{13} \mathrm{y}$ que a su vez, generen nuevos puestos de trabajo e instancias de investigación y desarrollo.

\section{Conclusiones}

La decisión de Evo Morales de nacionalizar los hidrocarburos el 1 de mayo de 2006 supuso un punto de inflexión en la "historia" del sector; no porque la misma no fuera implementada con anterioridad -de hecho se nacionalizó el sector en 1937 y 1969- sino por cómo se estableció este proceso y los objetivos gubernamentales que se persiguieron. A diferencia de las nacionalizaciones anteriores, el decreto 28701 de 2006 no impuso políticas confiscatorias o de expropiación de los bienes de los operadores transnacionales. En esta oportunidad, Evo Morales, a sabiendas de las dificultades que enfrentaba YPFB para encargarse de la totalidad de la cadena hidrocarburífera, optó por maximizar el control del Estado pero sin dejar de lado la inversión extranjera. La incorporación de la cláusula de "costos recuperables", conjuntamente con la existencia de destinos "seguros" dentro de la región para las exportaciones de las transnacionales, han sido los principales incentivos que proporcionó el Gobierno boliviano al momento de renegociar los contratos energéticos.

En cuanto a las implicancias en las relaciones con Argentina y Brasil -en su calidad de importadores- el proceso tuvo como punto de encuentro que "obligó" a las administraciones de Lula y Kirchner a adecuar sus acuerdos de compraventa a las disposiciones del decreto 28701 de 2006 ante la necesidad de continuar con el aprovisionamiento desde Bolivia. No obstante, cada negociación tuvo un sello propio.
La diplomacia brasilera hizo valer su condición de primer socio comercial y el peso de Petrobras en la industria energética boliviana. Así, mientras que Brasil logró sostener su participación en la producción hidrocarburífera de su vecino, el Gobierno argentino solo se limitó a garantizar la continuidad de las importaciones sin tener injerencia alguna en la actividad. Es más, pese a los impactos negativos de la crisis energética de 2004, el país no ha podido revertir la situación de dependencia gasífera que mantiene con Bolivia.

La redefinición del rol del Estado en la industria hidrocarburífera estuvo acompañada de otro objetivo: obtener un mayor control de la renta petrolera y a partir de allí, instaurar políticas que combatan la pobreza pero, al mismo tiempo, avancen hacia la industrialización del sector. Sin duda, este último punto es el gran desafío del Gobierno de Morales. Al presente, sin desconocer algunas acciones, tal como se indicó en el trabajo, del análisis del marco empírico se desprende que en un contexto de precios energéticos altos, el MAS ha realizado cambios en el modelo económico -mayor presencia del Estado- pero sin alterar el patrón de desarrollo.

Este hecho no es menor, ya que además de dar cuenta de cierto grado de fragilidad de la economía en general, afecta de manera directa o indirecta a los programas de transferencias monetarias que atienden las necesidades de las poblaciones vulnerables. Dichos programas, al estar solventados con un extractivismo intensivo -propio de una economía de "base estrecha"-, pueden quedar atrapados en el círculo vicioso que se genera con los altibajos de los precios internacionales de los commodities.

\section{Notas}

1 La "Guerra del Gas" -episodio que enfrentó al poder ejecutivo y la sociedad- fue resultado del rechazo de los intentos de exportación de gas licuado hacia Estados Unidos por puertos chilenos y "un símbolo del descontento 
hacia Sánchez de Lozada y sus fallidas promesas económicas" (Gordon \& Luoma, 2008, p. 101) de corte neoliberal. La sociedad se opuso a un proyecto que indirectamente atravesaba un punto sensible en la historia bilateral -Chile recibiría gas boliviano sin haber saldado el reclamo del país andino de salida al Pacífico- y además, era un negocio considerado poco beneficioso para el Estado, no así para las compañías transnacionales.

2 Dichos indicadores son una selección hecha por la autora a modo de referencia y para ilustrar la problemática que aquí se propone. Esto no le resta importancia a otros factores. Se recomienda consultar el trabajo de Monaldi (2010), quien analiza exhaustivamente estos cuatro ejes.

${ }^{3}$ La capitalización -que es una privatización- es una asociación entre el Estado y un inversionista, donde ambos aportan. El Estado aporta sus empresas, mientras que el inversionista proporciona un valor igual en capital y crea una nueva compañía, cuyo valor es el doble del valor original de la empresa pública. En cambio, la privatización corriente es "una transferencia directa de los activos del sector público al sector privado a cambio de una contraparte financiera percibida por el Estado" (Requena, 1996, p. 35).

4 Estos nuevos acuerdos deberían enmarcarse en las modalidades de contrato que propone la ley 3058 de 2005 . Estas son: contrato de producción compartida -el titular ejecuta por sus propios medios y a cuenta y riesgos exclusivos las actividades de exploración y explotación a nombre y representación de YPFB. El titular tiene una participación en la producción, en el punto de fiscalización, una vez deducidas regalías, impuestos y participaciones (art. 72, ley 3058 de 2005)-; contrato de operación -el titular ejecuta por sus propios medios, por exclusiva cuenta y riesgos y en representación de YPFB las actividades de exploración y explotación dentro de un área determinada según el sistema de retribución que puede ser un porcentaje de la producción, dinero o en especie (art. 77, ley 3058 de 2005)y contrato de asociación -es un contrato entre YPFB y un titular de un contrato de operación que puede surgir cuando este último efectúa un descubrimiento comercial. La participación del titular y YPFB sobre la producción se establece por contrato- (art. 81, ley 3058 de 2005).

5 Los costos recuperables permiten recobrar de manera indirecta parte de las inversiones hechas.

${ }^{6}$ Un contrato de servicios es un acuerdo entre una compañía petrolera y proveedores especializados que realizan determinados trabajos en materia de geociencias o ingeniería petrolera. No son convenios de exploración (OBIE-CEDLA, 2006, p. 2).

7 Un análisis minucioso de esta cuestión excede ampliamente los fines de este trabajo. Se recomienda consultar la investigación de Roberto Kozulj (2005).

8 Argentina se convirtió en proveedor de gas natural a Chile que, durante los noventa, estructuró su matriz energética con base en este hidrocarburo tras la suscripción del Protocolo Gasífero de 1995.

9 Ambos temas fueron tratados en el segundo mandato de Lula.

${ }^{10}$ Petrobras participa en múltiples áreas que han sido concesionadas dentro de los departamentos gasíferos bolivianos. Para mayor información sobre los contratos firmados, se recomienda consultar la Gaceta Oficial 2989 del Estado Plurinacional de Bolivia donde constan, con sus respectivas leyes de aprobación, los acuerdos suscriptos entre YPFB y Petrobras pos nacionalización.

${ }^{11}$ Este avance no implica ignorar que la pobreza y la desigualdad aún constituyen una temática preocupante en el país andino. 
12 Estos datos no dan cuenta de la calidad de la educación. Así mismo, se recalca que la Organización Panamericana de la Salud afirma que Bolivia continúa siendo uno de los países con una de las tasas de mortalidad maternoinfantil más altas de la región, sobre todo en zonas rurales.

${ }^{13}$ Por ejemplo, plásticos y fertilizantes.

\section{Referencias}

Acquatella, J.,Altomonte, H., Arroyo, A., \& Lardé, J. (2013). Rentas de recursos naturales no renovables en América Latina y el Caribe: evolución y participación estatal, 1990-2010 (CEPAL, Serie Seminarios y Conferencias No. 72). Santiago de Chile: CEPAL. Recuperado de http://archivo. cepal.org/pdfs/2013/S2013065.pdf

Agência Nacional do Petróleo, Gás Natural e Biocombustíveis -[ANP].(2013). Anuario Estadístico. Brasil: Autor. Recuperado de http://www.anp.gov.br/?pg=66833

Altomonte,H.,Acquatella,J.,Arroyo,A., Canales, C., \& Jouravlev, A. (2013). Recursos naturales. Situación y tendencias para una agenda de desarrollo regional en América Latina y el Caribe. Santiago de Chile: CEPAL. Recuperado de http://repositorio. cepal.org/bitstream/handle/11362/35891/ S2013807_es.pdf?sequence $=1$

Arze-Vargas, C. (2009). Los efectos perversos de la globalización neoliberal en Bolivia. En J. Crabtree, G. Gray-Molina \& L. Whitehead (Eds.), Tensiones irresueltas. Bolivia, pasado y presente (pp. 263-284). La Paz: Plural editores.

Carvajal, R. (21 de agosto de 2012). A monitorear los contratos petroleros. Bolpress. Recuperado de http://www. bolpress.com/art.php?Cod=2012082105
Estado Plurinacional de Bolivia. Decreto Supremo 24419 de 1996. Apruébase el Reglamento de Hidrocarburos Nuevos y Existentes. Gaceta Oficial No. 1961. Presidencia Constitucional de la República, noviembre de 1996.

Estado Plurinacional de Bolivia. Decreto Supremo 24806 de 1997. Apruébanse los modelos de contrato de riesgo compartido. Gaceta Oficial No. 2028. Presidencia Constitucional de la República, agosto de 1997.

Estado Plurinacional de Bolivia. Decreto Supremo 25588 de 1999. Adjudícase la Licitación Pública Nacional e Internacional Referencia MCEI/YPFB/UR/LIC 003/99 en favor del consorcio "Asociación Petrobras Bolivia S.A. "Pérez Companc International" en la suma de \$US 102.000.500. Gaceta Oficial No. 2182. Presidencia Constitucional de la República, noviembre de 1999.

Estado Plurinacional de Bolivia. Decreto Supremo 28701 de 2006. De Nacionalización de hidrocarburos "Héroes del Chaco". Gaceta Oficial No. 2883. Presidencia de la República, mayo de 2006.

Estado Plurinacional de Bolivia. Instituto Boliviano de Comercio Exterior -[IBCE]. (2013). Relación Comercial BoliviaBrasil. Boletín Electrónico Bisemanal, 229. Recuperado de http://ibce.org.bo/ images/ibcecifras_documentos/relacioncomercial-bolivia-brasil.pdf

Estado Plurinacional de Bolivia. Instituto Boliviano de Comercio Exterior -[IBCE]. (2014). Relación Comercial BoliviaArgentina. Boletín Electrónico Bisemanal, 358. Recuperado de http://ibce.org.bo/ images/ibcecifras_documentos/CIFRAS358-Relacion-comercial-BoliviaArgentina.pdf 
Estado Plurinacional de Bolivia. Instituto Nacional de Estadísticas -[INE]. (s.f). Bolivia: principales indicadores de empleo. Recuperado de http:// www.ine.gob.bo/indice/visualizador. aspx?ah=PC3040104.HTM

Estado Plurinacional de Bolivia. Instituto Nacional de Estadísticas -[INE]. (2012). Resultados del Censo Nacional de Población y Vivienda de Bolivia -[CNPyV]. Recuperado de http://www.ine.gob.bo:8081/ censo2012/PDF/resultadosCPV2012.pdf

Estado Plurinacional de Bolivia. Ministerio de Planificación del Desarrollo. (2006). Plan Nacional de Desarrollo. Recuperado de http://www.planificacion.gob.bo

Estado Plurinacional de Bolivia. Ley 1544 de 1994. Ley de Capitalización. Gaceta Oficial No. 1824. Honorable Congreso Nacional, marzo de 1994.

Estado Plurinacional de Bolivia. Ley 1689 de 1996. Ley de Hidrocarburos. Gaceta Oficial No. 1933. Honorable Congreso Nacional, abril de 1996.

Estado Plurinacional de Bolivia. Ley 3058 de 2005. Ley de Hidrocarburos. Gaceta Oficial No. 2749. Honorable Congreso Nacional, mayo de 2005.

Estado Plurinacional de Bolivia. Ley 3666 de 2007. Aprueba el Contrato de Operación suscrito en fecha 28 de octubre de 2006, por Yacimientos Petrolíferos Fiscales Bolivianos (YPFB) con "PETROBRAS BOLIVIA S.A.”. Gaceta Oficial 2989. Honorable Congreso Nacional, abril de 2007.

Estado Plurinacional de Bolivia. Observatorio Boliviano de Industrias Extractivas -[OBIE-CEDLA]. (2006). El patrón primario-exportador. Contratos que consolidan la vieja política neoliberal. Boletín
Informativo El Observador, 1(3), 1-8. Recuperado de http://www.cedla.org/sites/ default/files/boletin_el_observador_3 a1e1_diciembre_2006.pdf

Estado Plurinacional de Bolivia. Unidad de Análisis de Políticas Sociales y Económicas -[UDAPE]. (s.f.). Dossier Estadístico. Recuperado de http://www. udape.gob.bo/

Fernández-Saavedra, G. (2014). Ensayos sobre política exterior. La Paz: Plural editores.

Fernández-Terán, R. (2009). Gas, petróleo e imperialismo en Bolivia. La Paz: CESU; UMSS; IBP; Plural editores.

Gandarillas-Gonzáles, M. (2008). El cuarto oscuro de la privatización. En M. Gandarillas, M. Tahbub \& G. Rodríguez (Eds.), Nacionalización de los hidrocarburos en Bolivia. La lucha de un pueblo por sus recursos naturales (pp. 59-96). Barcelona: Icaria editorial.

Gordon, G., \& Luoma, A. (2008). Petróleo y gas: la riqueza ilusoria debajo de sus pies. En J. Shultz \& M. Crane Draper (Eds.), Desafiando la globalización. Historias de la experiencia boliviana (pp. 87-130). La Paz: El Centro para la Democracia; Plural editores.

Gray-Molina, G. (2006). La economía boliviana «más allá del gas». América Latina Hoy, $43,63-85$.

Hernández-Sampieri, R., Fernández-Collado, C., \& Baptista-Lucio, M. P. (2010). Metodología de la investigación. Perú: Mc Graw Hill.

Kozulj, R. (2005). Crisis de la industria del gas en Argentina (CEPAL, Serie Recursos naturales e infraestructura 88). Santiago de Chile: CEPAL. Recuperado de http://repositorio. 
cepal.org/bitstreamhandle/11362/6279/ S053153_es.pdf;jsessionid=FFA57F7EA 2E5367CF764FEB9EEA3A827?sequen $\mathrm{ce}=1$

Mayorga, F. (2008). El Gobierno del Movimiento al Socialismo en Bolivia: entre nacionalismo e indigenismo. En C. Moreira, D. Raus \& J. Gómez-Leyton (Coords.), La nueva política en América Latina: rupturas y continuidades (pp. 125-146). Montevideo: Ediciones Trilce.

Miranda-Pacheco, C. (2009). La importancia del gas en la economía boliviana. En J. Crabtree, G. Gray-Molina \& L. Whitehead (Eds.), Tensiones irresueltas. Bolivia, pasado y presente (pp. 191-212). La Paz: Plural editores.

Mokrani, L. (2008). El gas natural en el escenario regional. Umbrales, 17, 137-154.

Molina-Ortiz, F. (noviembre, 2013). Desarrollo y perspectivas del gas natural en América del Sur. Trabajo presentado en el "VIII Foro de Integración Energética Regional", Punta Cana.

Monaldi, F. (2010). La economía política del petróleo y el gas natural en América Latina (Plataforma Democrática, Working Paper No. 9). Recuperado de http://www. plataformademocratica.org/Publicacoes/18046_Cached.pdf

Morales, E. (22 de enero de 2006). Discurso de posesión del Presidente Constitucional de Bolivia, Evo Morales Ayma. Página 12. Recuperado de http://www.pagina12.com. ar/diario/especiales/18-62330-2006-01-30. html

Morales, E. (19 septiembre de 2006). Discurso del Presidente de la República Constitucional de Bolivia ante la Asamblea de Naciones Unidas. Recuperado de https:// documents-dds ny.un.org/doc/UNDOC/ GEN/N06/527/40/PDF/N0652740. pdf?OpenElement

Morales, J. (2008). La economía política del populismo boliviano del Siglo 21 (Documento de Trabajo No. 4). La Paz: Instituto de Investigaciones Socio-Económicas.

Nore, P. (1981). Cambios estructurales en la industria petrolera internacional. Algunas consecuencias para los países productores. Comercio Exterior, 31(11), 1249-1255.

Petrobras (31 de octubre de 2006). Contrato Petrobras-YPFB. Recuperado de http:// www.investidorpetrobras.com.br/ download/1486

República Argentina. (04 de mayo de 2006). Declaración Conjunta de la Cumbre de Presidentes de Puerto Iguazú. Recuperado de https://mrecic.gov.ar/node/31773

República Argentina. Energía Argentina Sociedad Anónima S.A. -[Enarsa]. (19 de octubre de 2006). Contrato de compra venta de gas natural Energía Argentina S.Ay Yacimientos Petrolíferos Fiscales Bolivianos Recuperado de http://www.enarsa.com.ar/images/pdf/ contrato_compra_venta_enarsa_ypfb.pdf

República Argentina. Instituto Argentino del Petróleo y del Gas -[IAPG]. (s.f.). Información Estadística. Reservas comprobadas de gas natural en millones de $m_{3}$. Argentina: Autor. Recuperado de http:// www.iapg.org.ar/estadisticasnew/reservasgaspais $2 . h t m$

Requena, M. (1996). La experiencia de privatización y capitalización en Bolivia (CEPAL, Serie Reformas de política pública 38). Santiago de Chile: CEPAL. Recuperado de http://repositorio.cepal. org/bitstream/handle/11362/9742/ S9600005_es.pdf?sequence $=1$ 
Ríos-Roca, Á. (2012). Rol del gas natural en el desarrollo económico y social de América Latina y el Caribe. Recuperado de http://www.olade.org/wp-content/ uploads/2015/08/Rol-gas-natural-desarrollo-ec-soc.pdf

Rodríguez-Cáceres, G. (2008). Alcances y límites de la tercera nacionalización. En M. Gandarillas, M. Tahbub \& G. Rodríguez (Eds.), Nacionalización de los hidrocarburos en Bolivia. La lucha de un pueblo por sus recursos naturales (pp. 97-142). Barcelona: Icaria editorial.

Ruiz-Caro, A. (2003). Tendencias recientes del mercado internacional del petróleo (CEPAL, Serie Recursos naturales e infraestructura No. 69). Santiago de Chile: CEPAL. Recuperado de http://repositorio. cepal.org/bitstream/handle/11362/6432/ S0311850 es.pdf;jsessionid=9B34E3B7 23121FBE3537C3E6F04B76ED?sequen $\mathrm{ce}=1$

Solíz-Rada, A. (9 de julio de 2003). El siniestro decreto 24806. Bolpress. Recuperado de http://www.bolpress.com/print. php?Cod $=2002069446 \& p=1$

Villegas-Quiroga, C. (2004). Privatización de la industria petrolera en Bolivia. Trayectoria $y$ efectos tributarios (3a. ed.). La Paz: CIDES-UMSA; CEDLA; FOBOMADE; DIAKONIA; Plural editores.

Wanderley, F. (2009). Más allá del gas: Entre la base estrecha y la base ancha. En J. Crabtree, G. Gray-Molina \& L.
Whitehead (Eds.), Tensiones irresueltas. Bolivia, pasado y presente (pp. 213-236). La Paz: Plural editores.

Yacimientos Petrolíferos Fiscales Bolivianos -[YPFB]. (2009). Distribución de reservas probadas y probables de gas natural por operador (al 01/01/2005) (Informe Técnico). Recuperado de http://www. ypfb.gob.bo/es/component/phocadownload/category/59-enero-diciembre-2009. $\mathrm{html}$ ?download=328: distribucion-de-reservas-probadas-y-probables-de-gas-naturalpor-operador-al-01-01-2005-gestion-2009

Yacimientos Petrolíferos Fiscales Bolivianos -[YPFB]. (2013a). Nacionalización: desarrollo para el pueblo (Informe Especial). Recuperado de http://www.ypfb.gob.bo/ component/phocadownload/category/72publicaciones.html?download $=451$ :informeespecial-mayo-2013

Yacimientos Petrolíferos Fiscales Bolivianos -[YPFB]. (2013b). Audiencia Pública. Rendición de Cuentas. Recuperado de http:// www2.hidrocarburos.gob.bo/index.php/ transparencia/audiencia-p $\% \mathrm{C} 3 \% \mathrm{BAblica} /$ category/33-audiencia-publica-agosto-2013. html?download $=205$ :yacimientos petroliferos-fiscales-bolivianos-ypfbagosto-2013

Zaratti, F. ( 2 de octubre de 2013). La nacionalización de los hidrocarburos en Bolivia: luces y sombras. Recuperado de https:// zaratti.wordpress.com/2013/10/02/lanacionalizacion-de-los-hidrocarburos-enbolivia-luces-y-sombras/ 